\title{
A GESTÃO DA CADEIA DE SUPRIMENTOS DAS REDES REGIONAIS DE VAREJO DE FRUTAS, LEGUMES E VERDURAS NO RIO GRANDE DO SUL: UM ESTUDO MULTICASO
}

\author{
Janaína Balk Brandão ${ }^{1}$ \\ Alessandro Porporatti Arbage ${ }^{2}$
}

\begin{abstract}
RESUMO
Este trabalho procura verificar os condicionantes das estruturas de governança na gestão da cadeia de suprimento das redes de varejo de frutas, legumes e verduras no estado do Rio Grande do Sul. O arcabouço teórico utilizado está baseado na Nova Economia Institucional, nas abordagens de Gestão da Cadeia de Suprimentos e nas Estratégias Competitivas das empresas organizadas em redes. Como nível de análise do trabalho, adota-se a cadeia de suprimentos das empresas varejistas. Neste Estudo de Caso, foram analisadas três redes regionais de varejo e seis fornecedores, abrangendo cinco mesorregiões do Estado. Verificou-se que as redes de varejo compõem estruturas de governança híbridas com diferentes níveis de coordenação, condicionadas pelas características impostas pela estratégia genérica adotada em cada rede, como forma de atender seus consumidores. Do ponto de vista dos agricultores percebeu-se que, conforme aumenta a exigência dos consumidores, proporcionalmente aumenta a necessidade de coordenação da cadeia, forçando ao desenvolvimento de investimentos específicos, o que causa aumento na dependência mútua. Esta tendência tem levado o varejo de alimentos, particularmente no que tange a frutas, legumes e verduras, a adotar uma postura mais colaborativa ao longo da cadeia.
\end{abstract}

Palavras-chave: estratégias competitivas, frutas, governança, legumes e verduras, redes de varejo.

\section{MANAGEMENT OF THE SUPPLY CHAIN OF FRUIT RETAIL REGIONAL NETWORKS, VEGETABLES IN RIO GRANDE DO SUL: MULTICASES STUDY}

\begin{abstract}
This thesis study aims to verify what conditions the adoption of governance structures in the formation and management of supplies chains in the networks of fruit and vegetables retail in the state of Rio Grande do Sul. For this, the main

\footnotetext{
${ }^{1}$ Graduada em Agronomia (UFSM). Mestrado e Doutorado em Extensão Rural (UFSM). Professora adjunta no DEAER-UFSM. E-mail: janainabalkbrandao@hotmail.com

${ }^{2}$ Graduado em Agronomia (UFSM). Mestrado em Economia Rural (UFRGS). Doutorado em Administração (UFRGS). Professor associado no DEAER-PPGExR da UFSM. E-mail: aparbage@yahoo.com.br
} 
question for this research is: What are the motivations that take to the structures of governance adopted in the supply chains of retail organizations for FLV? The theorical framework used to help in the comprehension of the complex relationships established in the competitive modern environment is based, above, in the New Institucional Economy, in the Theory of Transaction Costs in the approach of Management in Chain of Supplies and in the Competitive Strategies of network organizations. As a level of analysis the chain of supplies of the retail companies is adopted, from the perspective of internal chain until the interorganizational arrangements. The methodological option performed for this investigation is the Case Study, considering that three regional networks of retail and six suppliers were analysed, covering the area of five mesoregions of the state. This conjuncture has reflected on the raising of demand of these products and in the reorganization of all productive chain, reaching, specially, the initial link considered in this study: the farmers. As results it is verified that the retail networks when performing the management of their supplying chains use hibrid structures of governance with differente levels of coordination, considering the attributes of the transactions. But, also, conditioned by the characteristics imposed by the generic strategy adopted in each network as a way to answer their consumers. From the sight ocf impact on structuring the chains of supplies for the farmers it is seen that as the demand of the consumers gets higher, proportionally the need of coordinating the chain is increased, forcing the development of specific investments, increasing the mutual dependence. This takes the retail to adopt a more collaborative behavior in the chain.

Keywords: chain, competitive strategies, fruit and vegetables, governance, retail.

\section{INTRODUÇÃO}

As empresas, ao se prepararem para lidar com consumidores cada vez mais exigentes, estabelecem novos padrões de atuação e compõem arranjos colaborativos interorganizacionais. Neste sentido, além de aspectos estritamente organizacionais, como a definição do propósito do negócio, identificação dos principais concorrentes, a natureza dos recursos de produção a serem utilizados, o foco estratégico a ser adotado, entre tantas definições no âmbito interno, as organizações precisam considerar toda a dinâmica que envolve o contexto do encadeamento produtivo em que a mesma se encontra inserida.

$\mathrm{Na}$ ordem do dia percebe-se que a construção de estratégias mais duradouras está focada no 'valor' superior que é criado para o cliente e na busca em obter lealdade do consumidor em detrimento da concorrência (LOPES FILHO, 2006). Dentro deste contexto, o foco no estreito relacionamento com fornecedores, distribuidores, funcionários e consumidores finais, aliado a processos contínuos de aprendizagem, inovação e melhoria em tecnologias da informação são, certamente, elementos importantes na constituição de cadeias de suprimentos eficazes, capazes de oferecer um desempenho superior. Todavia, é necessário que se estabeleçam canais por onde passe a "voz do consumidor", encadeando os processos de produção de forma sincronizada com as sinalizações provindas da demanda.

Assim, as organizações procuram estabelecer formas de governança para constituir processos colaborativos entre os agentes. Para Suzigan, Garcia e Furtado (2007) a governança pode ser definida como a capacidade de comando ou 
coordenação que certos atores exercem sobre as inter-relações produtivas, comerciais, tecnológicas e outras, influenciando em seu desenvolvimento. Cassiolato e Lastres (2001) afirmam que as cadeias produtivas e de distribuição de mercadorias podem ser governadas por mecanismos de preços ou por forças hierárquicas impostas pelos atores atuantes no processo. Todavia, destaca a formação de estruturas intermediárias de governança, que podem resultar em maior grau de colaboração e cooperação entre as empresas.

Nesse contexto temático, o presente estudo pesquisa as motivações do estabelecimento das estruturas de governança no âmbito das cadeias de suprimentos de redes de varejo de frutas legumes e verduras no Rio Grande do Sul. Assim, o objetivo geral da pesquisa é verificar os condicionantes da composição e gestão das cadeias de suprimentos das redes regionais de varejo de frutas, legumes e verduras no Rio Grande do Sul. A questão de pesquisa que preside este debate se concentra em identificar se as cadeias de suprimentos dos referidos produtos são orientadas pela demanda ou por elementos relacionados com a oferta dos produtos, tendo em vista serem alimentos perecíveis e apresentarem, entre outras características distintivas, uma elevada frequência de compra por parte dos consumidores.

\section{CONTEXTUALIZAÇÃO DA REALIDADE}

\subsection{O VAREJO DE ALIMENTOS NO BRASIL}

Considerando a dinâmica contemporânea, passa a existir o debate sobre as novas configurações das organizações em um mundo globalizado com vistas a atender à diversidade do comportamento dos consumidores. Para Saab e Gimenez (2000), a existência de um número razoavelmente elevado de formas organizacionais de venda no varejo no Brasil é justificada pelas particularidades inerentes à distribuição dos produtos alimentares e pela organização dos canais visando à otimização do processo de distribuição.

Para Sproesser e Lima Filho (2007) a organização dos canais do varejo de alimentos pode ser definida de acordo com dois critérios essenciais: o comprimento do canal e a tecnologia de venda ao consumidor final (relacionada aos arranjos). Segundo o critério do comprimento do canal, pode-se ter o canal direto, indireto curto e indireto longo. Esse comprimento do canal é definido de acordo o número de agentes econômicos que o integram. No canal direto, o produtor garante o conjunto de atividades de distribuição junto aos consumidores, enquanto os canais indiretos comportam um número maior de elos intermediários. O canal indireto curto é composto de um produtor e de um varejista, enquanto o canal longo envolve, pelo menos, um agente intermediário.

Conforme Sproesser e Lima Filho (2007), o comprimento de um canal de distribuição é o resultado de escolhas econômicas efetuadas em função de múltiplos fatores, dos quais destacam-se a diversidade de comportamento dos consumidores, as particularidades inerentes à distribuição dos produtos perecíveis e o desejo de otimização do processo de distribuição. Esses elementos abonam a existência de um número razoável de arranjos organizacionais (SPROESSER; LIMA FILHO, 2007). 


\subsection{CARACTERÍSTICAS DO CONSUMO DE FRUTAS, LEGUMES E VERDURAS E AS DISTINTAS CONFIGURAÇÕES PARA ATENDER A DEMANDA DOS CONSUMIDORES}

Percebe-se que existe um estímulo por parte da mídia e de órgãos internacionais ao aumento do consumo de FLV. Essa incitação é evidenciada no relatório pericial independente sobre a dieta alimentar, que servirá de base para o desenvolvimento da Estratégia Mundial para o combate de doenças crônicas, em um esforço conjunto da Organização para a Alimentação e Agricultura das Nações Unidas (FAO) e a Organização Mundial de Saúde (OMS) ${ }^{3}$. Neste, a população é estimulada a ter uma dieta alimentar mais saudável, sendo que a ingestão diária de frutas, verduras e legumes deve ser de, pelo menos, 400 gramas/dia.

Os dados demonstram que no Brasil eram consumidos, em média, $29 \mathrm{~kg}$ de hortaliças ${ }^{4}$ por ano e $24 \mathrm{~kg}$ de frutas $^{5}$ segundo pesquisa do IBGE/Pesquisa de Orçamentos Familiares (POF) 2002-2003. Em pesquisa mais recente POF (20082009), verificou-se que o consumo de hortaliças e frutas é, respectivamente, em média, $24 \mathrm{~kg} / \mathrm{ano}$ e $31 \mathrm{~kg}$ frutas/ano. Somados os valores referentes às FLV, no início da década (2002-2003), tem-se um consumo médio per capita de 53 kg/ano. Já, ao final da década (2008-2009), o consumo passou para aproximadamente, 55 $\mathrm{kg} / \mathrm{ano}$, demonstrando leve aumento no consumo de frutas, mas o que compreende algo em torno de 150 gramas/dia.

E mais, o consumo de acordo com as classes de rendimento, apresenta importantes variações conforme salienta a publicação da POF (2008-2009). O consumo de várias frutas e verduras aumenta com a renda, como por exemplo, a banana $(15,4 \mathrm{~g}$ e $24,8 \mathrm{~g})$, maçã $(5,9 \mathrm{~g}$ e $18,3 \mathrm{~g})$, salada crua $(7,9 \mathrm{~g}$ e $21,8 \mathrm{~g})$ e tomate $(3,7 \mathrm{~g}$ e $10,0 \mathrm{~g})$ respectivamente. Entretanto, mesmo em famílias que possuem renda mais elevada, o consumo diário não ultrapassa 240 gramas, enquanto 0 recomendado está na ordem de 400 gramas $^{6}$.

Embora os dados de consumo estejam abaixo do recomendado, toda a conjuntura de estímulo crescente à ingestão de FLV em uma abordagem de saúde pública preventiva, o aporte do varejo com relação a comerciais de televisão, rádio, anúncios impressos, cartazes (FERNANDES, 2007) juntamente com a mudança nos hábitos alimentares dos brasileiros faz com que a seção de FLV venha ganhando importância no varejo. Melo e Vilela (2007) afirmam que a expectativa do consumidor é encontrar produtos frescos e comprá-los em lugar confiável, com mais conforto e flexibilidade de horário, o que tem exercido influência na dinâmica de distribuição dos produtos, impulsionando a venda desses produtos em supermercados, hipermercados e lojas de conveniências.

Dessa forma, para suprir habilmente os produtos demandados em um mercado exigente, dentro do período esperado, a parte 'para trás' da cadeia de suprimentos precisa estar adequadamente gerenciada. Isso tem levado a busca de

\footnotetext{
${ }^{3}$ Comunicado de Imprensa conjunto da OMS/FAO 23 de Abril 2003.

${ }^{4}$ Hortaliças folhosas e florais, frutosas e tuberosas.

${ }^{5}$ Frutas de clima tropical e temperado.

${ }^{6}$ O consumo também pode variar conforme o sexo e a idade, segundo publicação da Pesquisa de Orçamentos Familiares (POF) 2008-2009. Os homens registraram menores consumos per capita do que as mulheres para verduras, saladas e para grande das frutas. Por outro lado, os adolescentes registraram menor consumo diário per capita de saladas cruas $(8,8 \mathrm{~g})$ do que os adultos $(16,4 \mathrm{~g})$ e idosos $(15,4 \mathrm{~g})$. Esses dados são relevantes na medida em que tem aumentado a expectativa de vida da população.
} 
alternativas às tradicionais centrais de abastecimento ${ }^{7}$. Entre as principais alternativas visualizadas, estão o processo de verticalização da produção ou a compra diretamente dos produtores.

$\mathrm{Na}$ cadeia produtiva das FLV, predominam, historicamente, as transações via mercado. Nos últimos anos, porém, observam-se iniciativas que buscam novas formas de transação entre os agentes econômicos que vêm adotando estruturas de governança híbridas. Essas estruturas de governança apresentam uma ação de um agente coordenador do sistema, representado, nesse estudo, pela empresa focal: o varejo. Souza (2001) corrobora neste sentido quando conclui numa investigação sobre as estruturas de governança dos canais de comercialização de frutas, legumes e verduras no município de São Carlos-SP, onde os sacolões e supermercados vêm tendo o mesmo comportamento: há uma tendência em estabelecer parcerias diretamente com produtores de FLV sem que haja contratos formais de longo prazo.

Nas grandes redes de varejo, a comercialização realiza-se através das centrais de compras, nas quais os produtores entregam seus produtos na central de compras da rede de supermercado e são distribuídos para todas as lojas de rede. Ou seja, de qualquer maneira, Souza (2001) constatou a adoção de uma estrutura de governança híbrida. Belik e Chaim (2011) ao estudar a comercialização de hortifrutículas no Brasil também verificaram em todos os casos estudados que com o avanço da tecnologia e dos requisitos de qualidade estão surgindo formas híbridas de relacionamento entre produtores e distribuidores.

Entretanto, Belik (20..) destaca que a entrada dos competidores estrangeiros provocou mudanças radicais na forma de relacionamento com fornecedores, clientes e nas rotinas de aprovisionamento, sendo que essas mudanças são particularmente delicadas para o caso das FLV, devido às suas características e à dispersão na oferta, devendo ser analisadas como casos especiais. Dentre as formas supracitadas (mercado, híbrida e hierarquia) Belik (20..) destaca que, normalmente, as redes de supermercados têm procurado estabelecer formas de coordenação junto aos pequenos produtores que possam dar conta da necessidade de uma padronização de qualidade e também de garantias de regularidade e suprimento permanente para cada ponto de venda. $\mathrm{O}$ autor destaca ainda que estudos realizados em redes européias mostram que a percepção de qualidade por parte do consumidor está diretamente ligada à intensidade da integração entre produtores e redes de varejo. Isso tem levado os supermercados a intensificar esforços criando marcas próprias e fornecedores cativos para esses produtos, que cada vez pesam mais em termos de volume de vendas de contribuição para a margem de lucro.

\section{BASE CONCEITUAL DA PESQUISA}

Os aportes teóricos que abrangem o tema proposto na tese amparada neste estudo são delineados pelas contribuições da Nova Economia Institucional, especialmente a Economia dos Custos de Transação, os mecanismos de governança adotados e a coordenação estabelecida. A metodologia de análise e

\footnotetext{
${ }^{7}$ As Centrais de Abastecimento (CEASAs) foram criadas pelo governo federal na tentativa de organizar o setor em 1972, através do Decreto nำ 70.502. Foram estabelecidos mercados atacadistas nas principais cidades brasileiras. Tem como característica a economia mista, na qual participam a união; os estados; e os municípios.
} 
ferramentas utilizadas para o gerenciamento do sistema agroindustrial, também foram relevantes na interpretação dos fenômenos pesquisados. Primeiramente, sob uma perspectiva vertical, aborda-se a Gestão da Cadeia de Suprimentos e, numa perspectiva complementar, em um viés mais horizontal, a perspectiva intraorganizacional e suas estratégias como forma de obter vantagens competitivas.

Segundo as contribuições de Williamson (1989), as instituições econômicas do capitalismo têm o propósito fundamental de economizar os custos de transação ${ }^{8}$. Já o conceito de transação é definido por Williamson (1989) como a transformação de um bem ao longo de interfaces tecnologicamente separáveis, sendo a transação a unidade básica de análise, determinante na forma de organização.

Como características diferenciais do estudo de organização econômica, proposto por Williamson (op.cit), destaca-se o fato de a teoria estar ciente dos pressupostos comportamentais, introduzir a importância da especificidade dos ativos e considerar a empresa como uma estrutura de governança, definidas como o conjunto de regras que governam as transações. O autor ressalta que devemos dar atenção especial aos aspectos da organização (e não somente à tecnologia) e aos propósitos da eficiência (em oposição ao monopólio). Nesse sentido, ao apresentar um mapa cognitivo do contrato, Williamson (op.cit) destaca a ligação estreita da organização industrial enquanto campo de especialização que mais se associa a ECT, já que a organização industrial distingue adequadamente os propósitos do monopólio e da eficiência.

Considerando que as organizações vão formar arranjos de forma eficiente com o objetivo de reduzir custos de transação, o modelo de ECT tem como suporte as seguintes categorias de análise: os pressupostos comportamentais dos agentes (racionalidade limitada e oportunismo); os atributos das transações (especificidade de ativos, frequência e incerteza); e os fatores exógenos relacionados ao ambiente organizacional e ambiente institucional onde se insere a organização ${ }^{9}$.

\subsection{ESTRUTURAS DE GOVERNANÇA: MERCADO, HIERARQUIA E FORMAS HÍBRIDAS}

De acordo com as ponderações de Williamson (2005) os agentes fazem uso de mecanismos apropriados para regular uma transação com o objetivo de reduzir os custos de transação e em harmonia com as exigências do ambiente institucional. Esses 'mecanismos regulatórios' são descritos como estruturas de governança. Deste modo, Williamson (2005) salienta que com a finalidade de reduzir custos de elaboração e negociação de contratos, de mensuração e fiscalização da informação, de monitoramento do desempenho, e de organização das atividades, os agentes fazem uso de mecanismos apropriados para efetuar uma

\footnotetext{
${ }^{8}$ Os custos de transação são divididos em ex ante e em ex post. Os primeiros custos estão relacionados à redação, negociação e salvaguardas do acordo. Devido às lacunas que existirão, o documento será, via de regra, considerado incompleto, e as medidas de adaptação serão tomadas na medida em que surjam as contingências, conforme salienta Williamson (op.cit). Nos custos ex post estão incluídos os custos de má adaptação, quando as transações saem desalinhadas em relação ao contrato, os custos que são necessários pelas partes bilaterais para corrigir desvios de alinhamento ex post, os custos do estabelecimento e administração das estruturas de governança e, por fim, os custos para assegurar os compromissos.

${ }^{9}$ As principais críticas à ECT referem-se ao excessivo foco na redução dos custos, a subestimação dos custos de transação dentro das organizações e ao fato de não ter em grande conta as relações sociais existentes nas transações econômicas.
} 
determinada transação, também denominada na literatura econômica como estruturas de governança.

Entende-se que não existe uma estrutura de governança melhor que outra. As mesmas são adequadas às características da transação à qual estão relacionadas, ou seja, aos pressupostos comportamentais dos agentes e aos principais atributos das transações que condicionam os arranjos inter ou intraorganizacionais formados. Para Feltre e Paulillo (2006) os mecanismos de governança são compreendidos como as oportunidades de ações dos agentes coletivos e individuais num contexto no qual a representação e a distribuição dos interesses e a busca dos recursos de poder são fundamentais. Esse contexto pode ser determinado por fatores de ordem política, tecnológica, cultural, etc.

Nos dois extremos de uma linha imaginária das estruturas de governança, situam-se o mercado e a hierarquia. Contudo, as formas localizadas mais ao centro (híbridas) dessa linha são o foco desse estudo. Para Williamson (1989), a estrutura de governança deve ser concebida como uma matriz institucional na qual a integridade da transação é determinada ${ }^{10}$. Essa matriz é deliberada como o conjunto de regras, leis, contratos, normas formais e informais e condicionamentos internos às organizações que governam institucionalmente a transação. Ou seja, a matriz institucional também considera as diferentes características culturais e instituições que dão provimento em algum tipo de interação, afetando a transação.

Zylbersztajn (2005) considera que, na essência, a ECT analisa incentivos de eficiência com base nos arranjos institucionais, que podem ser tanto contratos formais, quanto as formas de coordenação informais, baseadas na reputação e laços sociais. Os contratos e as demais formas contratuais são definidos como uma forma de governança intermediária entre o mercado (agentes dispersos e sem investimentos específicos) e a hierarquia (onde as transações são internas).

Em suma, de acordo com as configurações estabelecidas para redução dos custos de transações, existem basicamente três tipos de estruturas que podem ser utilizadas pelos agentes econômicos nas transações: o mercado, a hierarquia e as estruturas híbridas. Exceto a primeira opção, os outros dois arranjos necessitam ser coordenados pelas organizações para que correspondam aos objetivos.

Para Pereira, Souza e Cário (2009), os diferentes arranjos, como mercado, hierarquia e relações contratuais (híbridos) são opções de governança disponibilizadas diante das características intrínsecas e extrínsecas a que estão submetidos os agentes. Assim, as transações via mercado são fundamentadas na lógica individual não cooperativa, enquanto a hierarquia internalizando as transações econômicas, subordina-as. Já as formas híbridas substituem o mercado, diante da especificidade de ativos e informação imperfeita, promovendo mecanismos de estímulo e controle de ações e de distribuição dos riscos de oportunismo. Dessa forma, a busca de melhor coordenação das interações no ambiente produtivo orienta a estruturação das formas institucionais na busca da redução dos custos e da incerteza.

\footnotetext{
${ }^{10}$ Como estruturas de governança, Azevedo (2000) destaca o mercado spot, contratos de suprimentos regular, contratos de longo prazo e a integração vertical. Somado a esses tipos, salienta-se ainda como estruturas de governança particulares as parceiras, redes verticais, redes horizontais, joint venture's, franquias, arranjos cooperativos e a coordenação vertical.
} 


\subsection{COORDENAÇÃO}

"A coordenação não é característica intrínseca dos sistemas produtivos, mas sim, uma construção dos agentes econômicos." (AZEVEDO, 2000, p. 35). Para esse autor, a caracterização da eficiência de um determinado sistema produtivo não depende somente de quão bem cada um dos seus segmentos desempenha suas funções e resolve seus problemas de produção. Assim, seguindo o raciocínio lógico da ECT, quanto mais apropriada for a coordenação entre os componentes do sistema, menores serão os custos de cada um deles, mais rápida será a adaptação às transformações do ambiente e menos custosos serão os conflitos inerentes às relações ao longo do canal de distribuição, desde o fornecedor até o cliente.

Segundo Azevedo (2000) a coordenação só assume importância se a especificidade de ativos $^{11}$ for diferente de zero. Caso contrário, os custos de transação seriam negligenciáveis, não existindo necessidade de controle sobre a transação, sendo o mercado a forma organizacional mais eficiente. De uma forma simplificada, pondera-se que o autor argumenta que, para especificidade baixa, o mercado será sempre mais eficiente e, conforme for aumentando a especificidade dos ativos, aumentará a dependência entre as partes, o que requer a necessidade de controle, acarretando em aumento dos custos de governança proporcionalmente.

Contudo, existe ainda uma forte conexão dos custos de coordenação com os demais atributos e os pressupostos comportamentais adotados na ECT. A racionalidade limitada afeta, de forma significativa, as relações estabelecidas no momento em que pode restringir as informações necessárias a uma determinada transação, assim como o oportunismo, que requer que sejam realizadas salvaguardas para evitar sua manifestação. Já a incerteza, para Azevedo (2000) tende a aumentar os custos de uma forma híbrida no momento em que, de um lado, exige adaptações cooperativas, o que não acontece com o mercado (que estaria mais sujeito a atitudes oportunistas) e, de outro, faz com que os problemas impostos pelas contingências precisem de uma solução consensual (o que não acontece na forma hierárquica).

\subsection{GERENCIAMENTO DO SISTEMA AGROINDUSTRIAL: METODOLOGIAS DE ANÁLISE E FERRAMENTAS}

Após o desenvolvimento dos trabalhos seminais (Commodity System Approach e Filière) e de uma série de outros aportes posteriores relacionados aos principais conceitos e às metodologias de análise utilizadas nos estudos agroindustriais $^{12}$, emergiu a necessidade de elaboração de ferramentas capazes de auxiliar na coordenação entre as atividades de produção e de distribuição como forma de dar respostas mais rápidas aos negócios. Essa demanda está inserida em um contexto que exige atenção das organizações, não só internamente, mas, sobretudo, no estreitamento das relações entre as organizações, já que suas fronteiras estão cada vez mais permeáveis. Bertaglia (2009) salienta que as empresas necessitam estar cada vez mais voltadas para os clientes, basearem-se em conhecimento e em informação, investindo em processos colaborativos, gerando soluções próprias ou em conjunto com outras organizações.

\footnotetext{
${ }^{11}$ Variável chave utilizada no modelo de Williamson (1989).

${ }^{12}$ Ver Arbage (2004).
} 
Borrás e Toledo (2006) argumentam que o conceito de cadeia de suprimento teve sua origem na logística ${ }^{13}$, onde inicialmente a ênfase era dada à facilitação da movimentação de materiais e coordenação da demanda entre fornecedor e cliente ${ }^{14}$. Entretanto, para Borrás e Toledo (2006), o conceito de gestão da cadeia de suprimentos está relacionando-se cada dia mais fortemente a outros conceitos como parcerias, alianças estratégicas e outras relações cooperativas entre os membros da cadeia de suprimento, resultando em aumento da ênfase dada aos fatores transacionais nela presentes.

Conforme Pires (2010), existem diversas definições de GCS, praticamente todas complementares e concebidas sob a perspectiva de seus autores. $\mathrm{O}$ autor afirma que a GCS é claramente multifuncional e abrange interesses de diversas áreas tradicionais das empresas. Assim, Pires (2010) considera a GCS como uma área contemporânea que, obviamente, tem mais de uma origem, citando pelos menos quatro vertentes: CGS como uma expressão de gestão da produção - sendo vista como uma expansão natural e necessária da gestão da produção e de materiais para além dos limites físicos da empresa; CGS como uma expansão da logística - parte da necessidade de muitos profissionais da área da logística expandir seu campo de atuação, conhecendo melhor a GCS como um todo para poder realizar os processos logísticos de forma efetiva e adequada; GCS como uma expansão do marketing - em função de identificação das necessidades do mercado e de desdobramento e passagem dessas demandas para a área de produção; GCS como uma expansão de compras - nesta perspectiva, a GCS pode ser entendida como uma expansão natural da área de compras, uma vez que cresce significativamente o volume de material comprado pelas empresas. Mesmo que Tan (2000) pondere que não existe ainda uma definição categoricamente consensual da GCS e suas atividades, destaca-se que a proposta central dessa noção, e utilizada neste trabalho, está relacionada ao fato de que, através do compartilhamento de informação e do planejamento conjunto entre os agentes, pode-se aumentar a eficiência ao longo do canal de distribuição aqui está a definição que será usada como GCS (BOWERSOX et al., 1996). A questão chave pode ser considerada a melhoria dos relacionamentos entre os agentes como forma de aumentar a competitividade através da criação de uma sintonia entre os elos, Assim, estruturase uma base teórica que possibilitada compreender a posição das empresas focais nas cadeias de suprimentos, com uma abordagem mesoanalítica, centrada nas organizações varejistas e seus parceiros à jusante e à montante.

Por fim, compete destacar o caráter inovador da 'filosofia gerencial' ou 'conjunto de processos gerenciais', elementos descritos por Mentzer et al. (2001) como definições categóricas pertinentes à GCS. Svensson (2002) corrobora neste sentido ao afirmar que a GCS está na infância e que ainda existe uma série de desafios a serem enfrentados tanto pelo ambiente acadêmico como pelo empresarial.

\footnotetext{
${ }^{13}$ Segundo o Council of Supply Chain Management Professionals, logística é definida como o processo de planejar, implementar e controlar, de maneira eficiente o fluxo e a armazenagem de bens, serviços e informação, relacionada, desde o ponto de origem até o ponto de consumo, com o propósito de atender as necessidades dos clientes. Fonte: <htpp://www.csmp.com>. Acesso em: dez de 2010.

${ }^{14}$ Borrás e Toledo (2006) realizam uma ótima pesquisa conceitual evolutiva das definições de cadeia de suprimentos, com seus respectivos autores e as diferentes escolas: escola de percepção da cadeia funcional; escola da interligação/logística; escola da informação; escola da integração/processo.
} 


\subsection{ESTRATÉGIAS COMPETITIVAS}

Após a percepção dos teóricos organizacionais acerca da importância do ambiente em que as empresas estão situadas, especialmente depois da década de 60 , ampliou-se o debate no que concerne à questão da estratégia numa atmosfera de negócios competitiva. Para Porter (1989), a estratégia competitiva é a busca de uma posição competitiva favorável, em um ambiente em que a concorrência está no âmago do sucesso ou do fracasso das empresas. Assim, a estratégia competitiva visa a estabelecer uma posição lucrativa e sustentável contra as forças que determinam a concorrência.

Em sua obra, Porter (1989) desenvolve a metodologia contida em Estratégia Competitiva de uma indústria como ponto de partida. E sua colaboração é particularmente importante nessa pesquisa, porque auxilia na compreensão da busca pelas organizações em criar e sustentar uma vantagem competitiva, através da implementação das estratégias genéricas. A vantagem competitiva surge fundamentalmente do valor $^{15}$ que uma empresa consegue criar para seus compradores e que ultrapassa o custo de fabricação pela empresa. Porter sugere que, a partir da concepção da indústria e da análise do comportamento do concorrente, as empresas podem criar meios de traduzir essa compreensão em uma vantagem competitiva. $O$ autor descreve que existem dois tipos básicos de vantagem competitiva (liderança em custos e diferenciação) que, combinados com o escopo de atividades para as quais a empresa procura obtê-los, levam a três estratégias genéricas para alcançar o desempenho acima da média: liderança em custo, diferenciação e enfoque. A proposição é que cada uma das estratégias genéricas envolve um caminho essencialmente diferente para a vantagem competitiva, combinando a escolha sobre o tipo de vantagem buscada com o escopo do alvo estratégico onde ela deva ser alcançada. Para tanto, a empresa deverá fazer uma escolha sobre qual o tipo de vantagem competitiva que busca obter e sobre o escopo dentro da qual irá alcançá-la.

Até recentemente, a compreensão da vantagem competitiva e da competitividade era baseada, sobretudo, nas posições fortes contra os desafios externos, maximização das competências essenciais e minimização das debilidades internas. Ou seja, a competição entre as firmas era o foco.

Porter (1989) afirma que os gerentes, frequentemente não consideram ou subestimam a probabilidade de que mudanças radicais ou descontínuas possam alterar, significativamente, a sua estrutura ou a vantagem competitiva de uma empresa. Contudo, salienta que a incerteza tem aumentado muito nos últimos anos, em decorrência de fatores como os preços flutuantes da matéria-prima, oscilações nos mercados financeiros, desregulamentação, revolução eletrônica e o crescimento da concorrência internacional. Para o autor, as fontes de incerteza são numerosas e se originam da própria indústria ou do seu meio ambiente mais amplo.

Considerando esse cenário descrito por Porter (1989) e utilizando uma visão que procura ir além do planejamento individual das empresas como método estratégico, Hitt (2003) ressalta que as empresas têm buscado ganhar vantagem competitiva através da cooperação. Isso acontece quando as empresas descobrem

\footnotetext{
${ }^{15}$ Para Porter, o valor é aquilo que os compradores estão dispostos a pagar, e o valor superior provém da oferta de preços mais baixos do que os da concorrência por benefícios equivalentes ou do fornecimento de benefícios singulares que mais do que compensam um preço alto.
} 
maneiras de combinar seus recursos e capacidades com os de outras empresas, com o objetivo de criar competências que os concorrentes consideram difíceis de entender e/ou imitar. Essa nova dinâmica surge como resposta às intensas e rápidas transformações presenciadas, relativas à economia, à tecnologia e à globalização das relações comerciais e culturais.

\section{MÉTODO}

A opção metodológica feita para esta investigação é o Estudo de Caso. O propósito do uso dessa forma de pesquisa está relacionado ao reconhecimento que o estudo de caso tem tido, sobretudo, na análise da complexidade dos fenômenos organizacionais. Segundo Yin (2001), o estudo de caso contribui de forma inigualável para a compreensão dos fenômenos individuais, organizacionais, sociais, políticos e até mesmo econômicos.

Nesse sentido, o fenômeno estudado refere-se às estruturas de governança estabelecidas pelas redes de varejo de FLV. Todavia, a verificação das motivações que levam às configurações hoje existentes e que acabam atribuindo os contornos das diferentes formas de coordenação da cadeia de suprimentos de FLV pode ser elencada como a principal questão de pesquisa.

Dado que o varejo brasileiro de alimentos possui cerca de $66 \%$ de médios e pequenos estabelecimentos ${ }^{16}$, esta pesquisa utilizou três organizações varejistas regionais que apresentam um porte médio. A relevância dos varejos regionais para este estudo também se dá pelo motivo de que na maior parte dos municípios do interior do estado são o tipo de varejo mais frequente, representando um volume muito significativo em termos de vendas e aquisição de FLV e, por consequência, um canal mais próximo das unidades produtivas locais. A definição de cada rede em particular se deu considerando a relevância da rede no recorte geográfico utilizado (buscou-se eleger as maiores empresas regionais) e com base nos contatos pessoais que a autora possuía.

Como forma de compreender a dinâmica que existe nas regiões localizadas fora do eixo produtor (Mesorregião Nordeste/Serra Gaúcha - Região Metropolitana), as distintas formas que as empresas utilizam para manter seu suprimento regular a longas distâncias e seus desafios de organização, o contexto das mesorregiões Centro Ocidental Rio-grandense, Centro Oriental Rio-grandense, Noroeste Riograndense, Sudoeste Rio-grandense e Sudeste Rio-grandense foram privilegiados neste estudo através da escolha de três empresas regionais presentes em diferentes municípios destas regiões ${ }^{17}$. Das sete mesorregiões sugeridas pelo IBGE, cinco mesorregiões foram incluídas por este estudo, abrangendo grande parte do território estadual. Após a seleção das regiões e a escolha das redes que foram analisadas e os respectivos fornecedores se deu com base na experiência da pesquisadora e através dos informantes das próprias redes. Desta maneira, como forma de compreender melhor os relacionamentos e as implicações para o setor produtivo, buscou-se que para cada rede se obtivesse pelo menos dois fornecedores, incluindo agricultores e atravessadores. Foram selecionados quatro casos referentes a

\footnotetext{
${ }^{16}$ ABRAS (2010).

${ }^{17}$ Mesorregiões geográficas definidas pelo Instituto Brasileiro de Geografia e Estatística/2009. Fonte: Fundação Economia e Estatística. Disponível em: <http://mapas.fee.tche.br>. Acesso em: setembro de 2011.
} 
produtores de olerículas que transacionam diretamente com as organizações varejistas escolhidas e dois casos de fornecedores estabelecidos na CEASA/POA.

\section{RESULTADOS E DISCUSSÃO}

A pesquisa demonstrou que as empresas de varejo estudadas representam o elo dentro da cadeia que toma a iniciativa de organizar o fluxo de produtos e informações de forma a atender as demandas dos consumidores. Para tanto, adotam estruturas de governança híbridas como mecanismo para realização de suas transações.

A via intermediária adotada pelas organizações varejistas, localizada entre o mercado e a hierarquia, não se apresentou de forma homogênea. Verificou-se que as empresas focais adotam posturas que podem variar dentro da estrutura de governança híbrida. Neste sentido, foram identificados distintos elementos que acabam definindo o tipo de relacionamento estabelecido em cada cadeia de suprimentos.

As organizações ao definirem requisitos mínimos, quais sejam: padrões de qualidade, volumes mínimos de fornecimento e uma condição de regularidade no fornecimento, definem o tipo de fornecedor capaz de atender a sua demanda. Desta maneira, incluem ou excluem determinados fornecedores, selecionando-os. Fica evidente então, que os relacionamentos são estabelecidos de forma cuidadosa, distinguindo-se da coordenação via mercado. Assim, a estrutura de governança híbrida estabelecida ao longo das cadeias de suprimentos é definida como forma de atender as exigências de cada rede em particular por meio do estabelecimento de relações diferenciadas com fornecedores, vistos como diferentes agentes, potencialmente capazes de disponibilizar o que é caro a cada uma das organizações.

Considerando esta conjuntura percebida, buscou-se averiguar as razões da adoção da cada estrutura de governança à luz da base conceitual empregada neste estudo.

Na Nova Economia Institucional e na Economia dos Custos de Transação, buscou-se os atributos capazes de explicar os diferentes comportamentos das empresas no âmbito competitivo. A frequência, caracterizada pela recorrência de uma transação, a incerteza, deliberada pelo desconhecimento das situações futuras, e a especificidade de ativos, citada como o principal elemento capaz de definir a necessidade de coordenação, constituem juntamente com os pressupostos comportamentais dos agentes a base sobre a qual as organizações se estruturam.

Conforme os pressupostos da ECT, a forma de organização dos agentes verificada nos casos estudados refere-se à estrutura híbrida. A frequência aparece como um atributo muito importante considerando que alinha os interesses dos varejistas e fornecedores de forma muito significativa, gerando uma dependência mútua. Entretanto, a alta frequência verificada nos mercados de perecíveis interfere também em outros três importantes elementos apontados pela teoria: a especificidade de ativos, a incerteza e o comportamento oportunista. Constatou-se que, baseados na alta frequência, mesmo estabelecendo diferentes níveis de coordenação, as empresas focais procuram constituir relacionamentos de longo prazo, reduzindo a incerteza dos elos, já que este procedimento tende a minimizar 
futuras ações oportunistas ${ }^{18}$. A alta frequência também favorece a realização de investimentos específicos por parte dos fornecedores. Neste ponto, percebe-se que a frequência torna propício o estabelecimento de parcerias, já que reduz a desconfiança entre as partes ao longo do tempo.

Todavia, a frequência das transações não difere entre os casos pesquisados. Desta forma, os demais atributos é que assumem uma particular importância na explicação dos arranjos percebidos.

Em relação à especificidade de ativos, verificou-se que este atributo não se apresentou de forma homogênea nos casos estudados. Pelo contrário, quanto maior a diferenciação dos produtos maior se mostrou a necessidade de realização de investimentos por parte dos fornecedores. Neste sentido, quanto mais exigente se mostra o cliente, proporcionalmente mais investimentos ao longo de todo processo produtivo e de distribuição devem ser despendidos por parte dos fornecedores. A exigência de regularidade de entrega para produtos sazonais também implica investimentos significativos. Por fim, não se deve desconsiderar que a capacidade de abastecer um volume alto também requer investimentos condizentes.

$\mathrm{Na}$ ECT a especificidade de ativos é considerada o mais importante determinante da estrutura de governança adotada, já que quanto maior a especificidade maior a dependência entre as partes. Nos casos estudados identificase uma linha decrescente em termos de investimentos específicos partindo dos fornecedores que atendem a demanda da rede que procura obter produtos com excelência em qualidade, seguida dos fornecedores que buscam aumentar a regularidade da oferta de produtos sazonais e, por fim, dos fornecedores que oferecem grande volume de produtos.

A possibilidade dos varejistas de não encontrar canais alternativos para o seu abastecimento (ou no caso dos fornecedores de não encontrarem canais de comercialização) além de inferir importância no que se refere aos investimentos específicos (especialmente ativos fixos, tais como: investimentos em sistemas de irrigação, estufas, caixaria, equipamentos de lavagem, câmaras frias, Box no CEASA, etc.), remete ao terceiro atributo das transações: a incerteza.

Neste sentido, a assimetria de informações relativas ao comportamento dos mercados mostrou-se como elemento importante. Mesmo que o elo coordenador da cadeia - varejo - apresente poder dentro da cadeia devido à escala de venda e ao contato direto com os consumidores, percebe-se que as empresas procuram garantir seu fornecimento de FLV de acordo com suas especificidades (seja no padrão de qualidade, no volume adequado, regularidade requerida, etc.) estabelecendo mecanismos de coordenação para além do mercado. Aliado aos fatores citados salienta-se o fato das FLV caracterizarem-se por produtos perecíveis, exigindo, deste modo, agilidade nos processos desde a produção até o consumidor.

Neste ponto, percebe-se a semelhança nos casos estudados. A necessidade de obter produtos que atendam a especificidade de sua demanda força os agentes a adotar uma estrutura de governança híbrida como forma de reduzir a incerteza. Contudo, o grau de coordenação variou conforme a exigência por qualidade ou preço. A procura da Rede 2 por fornecedores que atendam basicamente seu volume de produtos, levou a uma configuração mais próxima das relações de mercado. A Rede 1, por sua vez, busca fornecedores que atendam seu volume de compras mas a um custo mais baixo possível, o que levou a mesma

\footnotetext{
${ }^{18}$ Partindo-se do pressuposto que a dependência mútua reduziria os comportamentos oportunistas.
} 
transacionar diretamente com produtores, evitando elos intermediários. Todavia, a compra direta requer um esforço de organização da cadeia, considerando a necessidade de regularidade de suprimentos. Desta forma, a Rede 1 necessitou estabelecer arranjos que garantissem seu suprimento de forma regular, adotando uma estrutura de governança híbrida caracterizada comprometimento mútuo entre varejo e fornecedor. Já a Rede 3, com sua alta exigência por qualidade, chegou a uma alta coordenação da cadeia como forma de comprometer seus fornecedores, inclusive estabelecendo contratos formais. No município-sede a Rede 3 chegou a verticalizar a produção de FLV considerando a preocupação pela garantia de fornecimento contínuo de produtos de qualidade.

Pelo exposto, as formas de estruturar a cadeia decorrem tanto dos custos de transação, que incidem sobre cada estrutura de governança, quanto das motivações que cada rede de varejo possui, sobretudo em relação à padrões, necessidade de regularidade ou volume médios constantes. Cabe ressaltar que as diferenças na estruturação da governança não partem do elo produtivo, sendo uma resposta à demanda de mercado.

Como forma de atender às necessidades dos consumidores, as organizações varejistas de FLV gerenciam suas cadeias observando o seu foco estratégico. Ou seja, se a vantagem competitiva da rede está alicerçada na estratégica genérica da liderança em custo, como por exemplo, a Rede 1, a mesma estruturou sua cadeia de suprimentos com vistas a reduzir o número de elos, baixando o custo dos produtos. Porém, isso exigiu que a mesma coordenasse sua cadeia como forma de manter a oferta do seu suprimento regular. A preocupação demonstrada com relação à regularidade na Rede 1 está ligada ao fato de que a mesma por transacionar prioritariamente com produtores sente muito o impacto da sazonalidade, já que isso resulta em ruptura de abastecimento, fazendo com que procure fornecedores inclusive em outros estados.

A Rede 2 embora esteja buscando uma melhoria de qualidade de seus produtos, destaca-se por ser um supermercado que busca atender à públicos de renda definida, o que lhe confere características de uma estratégia baseada no enfoque. Desta forma, a Rede procurou estabelecer uma estrutura de governança que atenda em primeiro plano suas necessidades em volume, optando por um número muito reduzido de fornecedores e pela logística verticalizada. Para a Rede 2 o fato de escolher grandes fornecedores reduz seus custos de transação ao mesmo tempo em que atende sua estratégia genérica, já que está localizada numa zona intermediária entre a qualidade(diferenciação) e o preço baixo (custo).

A Rede 3 que apresentou o maior nível de coordenação da cadeia procura disponibilizar para seus clientes produtos diferenciados em termos de qualidade, o que exige uma estruturação também diferenciada nas formas de gestão e organização da cadeia de suprimentos. A Rede 3 demonstrou maior complexidade nos relacionamentos (estabelecendo relações formais e informais), envolvendo o maior número de elos e utilizando vários comprimentos ao longo dos canais de distribuição simultaneamente. Desta maneira, observa-se que quando se aumenta o nível de exigência dos produtos, mais difícil se torna o abastecimento, levando a empresa focal a formar complexos arranjos como forma de atender as suas demandas.

Como semelhança entre as estruturas de governança adotadas nos casos pesquisados destaca-se que as iniciativas dos elos varejistas procuram reduzir os níveis de incerteza, ao mesmo tempo em que buscam minimizar os comportamentos 
oportunistas dos fornecedores através do estabelecimento de relacionamentos duradouros. Por outro lado, observa-se que, mesmo híbridas, as estruturas podem estar mais ou menos próximas das relações de mercado conforme o mecanismo de coordenação que é utilizado. Entretanto, o mecanismo de coordenação procura reduzir os custos de transação, mas também atender o foco estratégico da empresa.

Entre os mecanismos de coordenação utilizados nos casos analisados destaca-se o acompanhamento da produção como forma de obter a regularidade de oferta desejada - Rede 1; a definição de uma escala mínimia, referente ao 'porte' do fornecedor - Rede 2; e o financiamento, a assistência técnica e a padronização de um nível de qualidade- no caso da Rede 3; O mecanismo da padronização dos produtos mostrou-se relevante para todas as empresas pesquisadas, porém ressaltado de forma mais enfática na Rede 3, que exige um alto padrão.

No que se refere à exigência do varejo pela padronização nota-se que isso é uma reivindicação que cai sobre o fornecedor e, em efeito cascata, recai sobre o produtor. Fica claro que o varejo não quer assumir o desperdício que seria selecionar os produtos após entrar em seu depósito, exigindo cada vez mais que o fornecedor entregue seus produtos uniformes. Essa cobrança implica em última instância no produtor que deve trabalhar cada vez mais no sentido de tecnificar sua produção ou, elaborar estratégias para o aproveitamento do que é recusado pelo varejo. A última alternativa foi verificada apenas no caso do Fornecedor 5 considerando que o mesmo estabeleceu uma agroindústria para fabricação de batata palha.

Quanto às formas de coordenação cabe destacar ainda o alto grau de informalidade nas relações ao longo da cadeia, provocadas especialmente pelo poder das empresas varejistas em termos de escala de compra muito significativa, o que atrai e 'fideliza' muitos fornecedores. Todavia, a falta de contratos formais pode levar os agentes ao vislumbrarem transações mais compensadoras a adotarem um comportamento oportunista.

\section{CONCLUSÕES}

Sucintamente pode-se afirmar que os resultados obtidos implicam contribuições teóricas e práticas. Do ponto de vista teórico, pondera-se que as organizações de varejo estruturam suas cadeias de suprimentos considerando seus custos de transação em sintonia com o foco estratégico tomado. Ou seja, além do impacto da frequência, da incerteza e da especificidade de ativos a definição das formas organizacionais adequadas se dá de acordo com as exigências estabelecidas pela estratégia genérica adotada pela rede: custo, enfoque ou diferenciação. Decorrente do tipo de vantagem competitiva elegida pelo elo coordenador poder-se-á ter arranjos diferenciados dentro de uma mesma estrutura de governança, mesmo considerando que as redes possuem um mesmo porte e estão inseridas dentro de um ambiente institucional similar. Isso corrobora na explicação do porquê que organizações varejistas de mesmo porte estruturam de forma particular suas cadeias de suprimentos, visto que o foco das exigências que se quer satisfazer dos clientes é diferente.

Sob a perspectiva prática, sustenta-se que conforme aumenta a exigência dos consumidores proporcionalmente aumentará a necessidade de coordenação da cadeia para satisfazê-las e, assim, maior será a necessidade de que se desenvolvam ativos específicos como forma de atender as particularidades das 
demandas. Desta forma, quanto maior a necessidade de especificidade ativos, maior será a dependência entre as partes, reduzindo o comportamento oportunista dos agentes.

\section{REFERÊNCIAS}

AZEVEDO, P. F. Nova economia institucional: referencial geral e aplicações para a agricultura. Agricultura: São Paulo, SP, 2000.

BELIK, W.; CHAIM, N. A. Formas híbridas de coordenação na distribuição de frutas, legumes e verudras no Brasil. Disponível em: < http://www.wco.unicamp.br/artigos/artigo173.htm>. Acesso em: maio de 2011.

BELIK, W. Aumento da renda muda perfil nutricional da população brasileira. Entrevista concedida à: Mobilizadores COEP: uma rede de incentivo ao exercício da cidadania. Disponível em: <http://www.mobilizadores.org.br/coep/Publico/consultarConteudo.aspx?TP=D\&COD IGO=C2011823112114849>. Acesso em: setembro de 2011.

BELIK, W. Supermercados e produtores: Limites, Possibilidades e Desafios. 20. Disponível em:< http://www.sober.org.br/palestra/12/070078.pdf> Acesso em: janeiro de 2011.

BERTAGLIA, P. R. Logística e gerenciamento da cadeia de abastecimento. 2 ed. ver. e atual. - São Paulo: Saraiva, 2009.

BORRÁS, M. A. A.; TOLEDO, J. C. A coordenação de cadeias agroindustriais: garantindo a qualidade e competitividade no agronegócio. In: ZUIN, L. F. S.; QUEIROZ, T. R. Agronegócios: gestão e inovação. São Paulo: Saraiva, 2006.

BOWERSOX, D.; et al. Logistical management: a integrated system. 3. ed.Mc Graw-Hill, 1996.

CARVALHO, A. P.; VIEIRA, M. M. F.; LOPES, F. D. Contribuições da perspectiva institucional para análise das organizações. Anais do XXIII Encontro Nacional de Programas de Pós-Graduação em Administração - ENANPAD, Foz do Iguaçu, 1999.

CASSIOLATO, J. E.; LASTRES, H. M. M. Aglomerações, cadeia e sistemas produtivos de inovação. Brasília: IEL, 2001.

FELTRE, C.; PAULILLO, L. F. Contribuição para a Análise dos Mecanismos de Governança na Produção Rural. In: ZUIN, L. F. S.; QUEIROZ, T. R. Agronegócio: gestão e inovação. São Paulo: Saraiva, 2006.

FERNANDES, R. M. P. A participação do merchandising no processo de compra dos consumidores em supermercados. 2007, 158f. Dissertação (Mestrado em Comunicação Social) Universidade Metodista de São Paulo. São Bernardo do Campo, 2007. 
HITT, M. A. Administração estratégica: competitividade e globalização. Tradução de José Carlos Barbosa dos Santos e Luiz Antonio Pedroso Rafael. In: HITT, M.; IRELAND, R. D.; HOSKISSON, R. E.; São Paulo: Pioneira Thomson Learning, 2003.

LOPES FILHO, L. S. Marketing de vantagem competitiva. São Paulo: Saraiva, 2006.

MELO, P. C.; VILELA, N. J. A importância da Cadeia Produtiva Brasileira de Hortaliças. In: Sociedade Brasileira de Economia, Administração e Sociologia Rural. Rio Branco, 2007. Disponível em: <http://www.abhorticultura.com.br/downloads/cadeia_produtiva.pdf>. Acesso em: 27 set 2009.

MENTZER, J. T.; et al. Defining supply chain management. In: Journal of Business Logistics. v. 22, n. 2, 2001.

OMS Comunicado de imprensa conjunto da OMS/FAO 23 de abril 2003. Disponível em: http://who.int/nutrition/publications/pressrelease32_pt.pdf. Acesso em: out de 2009.

PEREIRA, L. B.; SOUZA, J. P.; CÁRIO, S. A. F. Elementos básicos para estudo de cadeias produtivas: tratamento teórico analítico. In: PRADO, I. N.; SOUZA, J. P. Cadeias produtivas: estudos sobre competividade e coordenação.2. ed. Maringá: Eduem, 2009.

PIRES, S. R. I. Gestão da cadeia de suprimentos: conceitos, estratégias, práticas e casos. 2. ed. Pão Paulo - Atlas, 2010.

POF. Pesquisa orçamentos familiares. Disponível em: <http://www.ibge.gov.br/home>. Acesso em: ago 2011.

PORTER, M. E. Vantagem competitiva: criando e sustentando um desempenho superior. Rio de Janeiro: Campus, 1989.

SAAB, W. G.; GIMENEZ, L. C. Aspectos atuais do varejo de alimentos no mundo e no Brasil. BNDES Setorial, n. 11, março de 2000. Disponível em: $<\mathrm{http}: / /$ www.bndes.gov.br/conhecimento/bnset/set1106.pdf>. Acesso em: novembro de 2009.

SOUZA, R. C. As estruturas de governança dos canais de comercialização de frutas, legumes e verduras no município de São Carlos, estado de São Paulo. In: Informações Econômicas, SP, v. 31, n. 11, Nov. 2001.

SPROESSER, R. L.; LIMA FILHO, D. O. Varejo de alimentos: estratégia e marketing. In: BATALHA, M.O. Gestão agroindustrial. 3. ed. São Paulo: Atlas, 2007. 
SUZIGAN, W.; GARCIA, R.; FURTADO, J. Estruturas de governança em arranjos ou sistemas locais de produção. Revista Gestão e Produção, São Carlos, v. 14, n. 2, p. 425-439, maio/ago.2007.

SVENSSON, G. The theoretical foundation of supply chain management: a functionalist theory of marketing. In: International Journal of Physical Distribution \& Logistic Management. v. 7, p. 39-48, 2002.

TAN, K. A framework of supply chain management literature. In: Europe Journal of Purchasing e Supply Management. v. 7, p. 39-48, 2000.

WILLIAMSON, O. E. Las instituciones económicas del capitalismo. México: Fondo de Cultura Economica, 1989.

WILLIAMSON, O. E. Transaction cost economics. In: MENARD, C. SHIRLEY, M. Handbook of new institutional economics. New York: Springer, p. 41-68, 2005.

WILLIAMSON, O. E. Markets and hierarchies: analysis and anti-trust implications, New York: Free Press, 1975.

YIN, Robert K. Estudo de caso: planejamento e métodos. Trad. Daniel Grassi, 2. ed., Porto Alegre: Bookman, 2001.

ZYLBERSZTAJN, D. Papel dos contratos na coordenação agro-industrial: um olhar além dos mercados. Anais do XLIII Congresso da Sociedade Brasileira de Economia e Sociologia Rural. São Paulo, 2005. 